\title{
Effect of Debarking Water from Norway Spruce (Picea abies) on the Growth of Five Species of Wood-Decaying Fungi
}

\author{
Amelie Fagerlund Edfeldt ${ }^{\mathrm{a}}$, Erik Hedenström ${ }^{\mathrm{a}, *}$, Mattias Edman ${ }^{\mathrm{b}}$, and Bengt \\ Gunnar Jonsson ${ }^{\mathrm{b}}$ \\ a Eco-Chemistry, Department of Chemical Engineering, Mid Sweden University, \\ SE-851 70 Sundsvall, Sweden. Fax: +46601488 02. E-mail: erik.hedenstrom@miun.se \\ b Department of Natural Sciences, Mid Sweden University, SE-851 70 Sundsvall, Sweden \\ * Author for correspondence and reprint requests
}

Z. Naturforsch. 69c, 418 - 424 (2014) / DOI: 10.5560/ZNC.2014-0072

Received April 4 / August 2, 2014 / published online September 24, 2014

\begin{abstract}
Norway spruce (Picea abies) debarking water is an aqueous extract obtained as waste from the debarking of logs at paper mills. The debarking water contains a mixture of natural compounds that can exhibit diverse biological activities, potentially including fungicidal activity on some species of wood-decaying fungi. Thus, we investigated the growth rates of such fungi on agar plates to which debarking water extracts had been added. The experiment included five wood-decaying fungi, viz. Gloeophyllum sepiarium, Oligoporus lateritius, Ischnoderma benzoinum, Junghuhnia luteoalba, and Phlebia sp. Growth reduction was observed for all species at the highest tested concentrations of freeze-dried and ethanol-extracted debarking water, the ethyl acetate-soluble fraction and the diethyl ether-soluble fraction. However, the magnitude of the effect varied between different species and strains of individual species. The brown-rot fungi $G$. sepiarium and $O$. lateritius were generally the most sensitive species, with the growth of all tested strains being completely inhibited by the ethyl acetate-soluble fraction. These results indicate that development of antifungal wood-protecting agents from debarking water could potentially be a way to make use of a low-value industrial waste.
\end{abstract}

Key words: Norway Spruce, Debarking Water, Wood-Decaying Fungi

\section{Introduction}

Wood-decaying fungi are dominant dead-wood decomposers, providing recycling of nutrients and carbon (Harmon et al., 1986) as well as providing seed beds for other organisms in the forest ecosystem (Tedersoo et al., 2008; Yelle et al., 2008). Wood is also a vital raw material for pulp, paper, and construction industries among others, and thus wood protection is an important research area (Schultz et al., 2007). Wood-decaying fungi decompose cellulose, hemicellulose, and lignin of living trees, commercial timber, and wood products, while molds and other fungi may cause discolouration of the wood and thus lower its economic value (Bowyer et al., 2003; Goodell, 2003; Messner et al., 2003). Different wood-decaying fungi use various secreted decomposing enzymes such as cellulases, hemicellulases, lignin peroxidase, manganese- dependent peroxidase, and laccase (Suzuki et al., 2006; Yelle et al., 2008). But, as the enzymes are too large to penetrate the unmodified cell walls of healthy wood the decay process therefore must be preceded by a nonenzymatic process. It is considered that reactive oxygen species and the Fenton reaction might be involved in the decay mechanism (Green and Highley, 1997; Leonowicz et al., 1999).

Bark from tree species is a rich source of antioxidants and antimicrobial agents, such as waxes, resins, phenols, and tannins. The bioactivity of extracts from bark from different sources will vary, as has been shown in studies involving the evaluation of antifungal properties of bark from several tree species (Yang et al., 2004; Yang, 2009). Phenolic compounds are well documented as antimicrobial agents (Duke, 1985). Phenol extractives of spruce origin have antioxidant activity (Co et al., 2012) and might also act as fungi- 
cides on various species of wood-decaying fungi. The site(s) and number of hydroxy groups on the phenol ring are thought to be related to their relative bioactivity, and increasing hydroxylation usually results in increased antimicrobial effects (Geissman, 1963). Also, there are suggestions that oxidized phenols are potent inhibitors, with enzyme inactivation being one of the possible mechanisms of toxicity (Mason and Wasserman, 1987).

Debarking water is a waste from the debarking of logs at paper mills. At the thermo-mechanical pulping (TMP) Ortviken paper mill in Sundsvall, Sweden, the debarking of spruce logs is facilitated by spraying them with water heated to $37^{\circ} \mathrm{C}$. After pressing out the water from the removed bark, one obtains the debarking water which is a brown, thick extract that is considered as waste. The water-soluble or partly watersoluble substances in these waste waters are predominantly mono- and oligosaccharides, hydroxystilbenes and their glucosides, catechins, polyphenols, and resin acids (Kylliäinen and Holmbom, 2004). At present, there is no commercial use for this natural chemical resource. Like some other waste waters in the paper industry, it contains wood substances with a negative impact on the factory's biological cleaning system, and thus represents an environmental risk (Allen and Back, 2000). If useful compounds could be recovered from the debarking water, it would add value to the costly and complicated waste management.

The aim of this study was to investigate a possible inhibitory effect of debarking water from Norway spruce (Picea abies) on the growth rate of five species of wood-decaying fungi growing on agar plates, viz. Gloeophyllum sepiarium, Oligoporus lateritius, Ischnoderma benzoinum, Junghuhnia luteoalba, and Phlebia sp., which were chosen because they represent different ecological strategies and differ in their fungal properties. To our knowledge, the antifungal properties of debarking water have not been investigated against wood-decaying fungi previously. This screening study should be seen as a first step towards the identification of a new potential wood-protecting system and, if successful, the commercial use of debarking water.

\section{Materials and Methods}

\section{Chemicals and instrumentation}

Agar, malt extract, and magnesium sulfate were purchased from Sigma-Aldrich (Steinheim, Germany). Ammonium nitrate and potassium dihydrogen phosphate were obtained from Merck (Darmstadt, Germany). Ethyl acetate was purchased from Fisher Chemicals (Waltham, MA, USA). Ethanol, diethyl ether, dichloromethane, and $n$-pentane were purchased from WVR (Radnor, PA, USA). All solvents were of high-performance liquid chromatography (HPLC) grade or were distilled before use. Debarking water from Norway spruce [Picea abies (L.) H. Karst.] bark was obtained from the TMP Ortviken paper mill in Sundsvall, Sweden.

Thin-layer chromatography (TLC) was performed using Fluka silica gel on TLC aluminium foils (SigmaAldrich), with various mixtures of ethyl acetate and cyclohexane as mobile phases. HPLC-mass spectroscopy (MS) analyses were performed on an Agilent 1290 infinity HPLC system equipped with a photodiode array detector and a 6520 Accurate mass-Q-TOF mass spectrometer (Santa Clara, CA, USA). The system was fitted with an Agilent Zorbax Eclipse plus C-18 rapid resolution HD $2.1 \times 100 \mathrm{~mm} 1.8$ micron column and eluted using a methanol/water gradient containing $0.1 \%(\mathrm{v} / \mathrm{v})$ formic acid. Freeze-drying was performed with a Christ Alpha 1-4 unit (Abex instruments, Osterode/Harz, Germany).

\section{Fungi}

We tested five species of saprotrophic basidiomycetes that decompose conifer wood: Gloeophyllum sepiarium (Wulfen) P. Karst., Oligoporus lateritius (Renvall) Ryvarden \& Gilbertsson, Ischnoderma benzoinum (Wahlenb.) P. Karst., Junghuhnia luteoalba (P. Karst.) Ryvarden, and Phlebia sp. (Pers.). The first two species are brown-rot fungi, while the latter three are white-rot fungi. The studied species have different preferences in terms of the decay stage of the wood: $G$. sepiarium prefers fairly fresh wood, J. luteoalba and $O$. lateritius prefer moderately decayed wood, and $I$. benzoinum prefers wood in the later stages of decay (Renvall, 1995). The wood preferences of Phlebia sp. are not known. Three strains of $G$. sepiarium and $J$. luteoalba, two strains of I. benzoinum, and one strain each of O. lateritius and Phlebia sp. were tested. All cultures were maintained on plates of malt extract agar prior to experimental use. The tested fungal strains are maintained in the Mid Sweden University Fungal Collection.

\section{Preparation of agar plates}

After evaporation of the solvent, the dry substances obtained from the debarking water were weighed into 
bottles. The agar solution was autoclaved and then mixed with the substances while still warm. The resulting mixture was directly poured into $9-\mathrm{cm} / 25-\mathrm{mL}$ sterile Petri dishes and allowed to cool. Control dishes were prepared in the same way but without the addition of debarking water substances.

The concentrated solvent fractions were analysed by NMR spectroscopy to determine the residual solvent content before adding them to the agar plates. Aside from the ethyl acetate extracts used in experiment 2 , all of the fractions were found to be free of residual extraction solvent. The antifungal activity of ethyl acetate itself was therefore investigated; it was found to have a very modest inhibitory effect relative to the control, and this was deemed insufficient to meaningfully affect the evaluation of the experimental results.

\section{Experiment 1}

An 1-L sample of debarking water was freeze-dried at $-50{ }^{\circ} \mathrm{C}$ and $10 \mathrm{kPa}$ for $48 \mathrm{~h}$. The freeze-dried powder (dry weight: $42.7 \mathrm{~g}, 4.3 \% \mathrm{w} / \mathrm{w}$ of the debarking water) was extracted with ethanol $(600 \mathrm{~mL}, 95 \%)$ for $24 \mathrm{~h}$ and then filtered to remove any undissolved material, after which the ethanol was evaporated off (yield: $24.4 \mathrm{~g}, 57 \% \mathrm{w} / \mathrm{w}$ of the dry weight of the debarking water). Agar plates containing three concentrations of the dried ethanol extract $(0.116 \mathrm{~g} / \mathrm{L}, 1.16 \mathrm{~g} / \mathrm{L}$, and $11.6 \mathrm{~g} / \mathrm{L}$, corresponding to approximately 5,50 , and $500 \mathrm{mg}$, respectively, of the dry weight of the debarking water per agar plate) were prepared.

\section{Experiment 2}

A 2-L sample of debarking water was sequentially extracted with $n$-pentane $(3 \times 670 \mathrm{~mL})$ and ethyl acetate $(3 \times 670 \mathrm{~mL})$. The two organic extracts were separately dried over $\mathrm{MgSO}_{4}$, filtered, and the solvent was evaporated off. The remaining debarking water was concentrated to $1 / 10$ of its initial volume. Ethanol was added to a final concentration of $80 \%(\mathrm{v} / \mathrm{v})$ after which the mixture was extracted for $24 \mathrm{~h}$, filtered, and evaporated to remove the remaining solvent. The $n$-pentane extraction yielded $0.857 \mathrm{~g}$ of dry material and the ethyl acetate extraction yielded $6.18 \mathrm{~g}$ (corresponding to yields of $1.1 \%$ and $7.7 \%$, respectively, based on the dry weight of the debarking water sample). The water/ethanol extract was not fully dried, and so its yield was not calculated. Agar plates containing $0.428 \mathrm{~g} / \mathrm{L}$ of the dried $n$-pentane extract, $3.09 \mathrm{~g} / \mathrm{L}$ of the dried ethyl acetate extract, or an amount of the water/ethanol extract corresponding to approximately $1 \mathrm{~g}$ of the dry weight of the debarking water were prepared.

\section{Experiment 3}

A 2-L sample of debarking water was first extracted with $3 \times 670 \mathrm{~mL}$ of $n$-pentane, to remove the $n$-pentane-soluble substances from the extract. This fraction was discarded. The remaining water extract was sequentially extracted with diethyl ether, dichloromethane, and ethyl acetate. The latter three extracts were dried over $\mathrm{MgSO}_{4}$ and filtered, after which the solvent was evaporated. The diethyl ether, dichloromethane, and ethyl acetate extracts furnished $2.59 \mathrm{~g}(3.2 \%), 0.70 \mathrm{~g}(0.9 \%)$, and $2.60 \mathrm{~g}(3.2 \%)$ of dry material, respectively, based on the dry weight of the debarking water. Agar plates containing $1.42 \mathrm{~g} / \mathrm{L}$ of the dried diethyl ether extract, $0.38 \mathrm{~g} / \mathrm{L}$ of the dried dichloromethane extract, or $1.43 \mathrm{~g} / \mathrm{L}$ of the dried ethyl acetate extract, corresponding to $1.1 \mathrm{~g}$ of the dry weight of the debarking water were prepared.

\section{Experimental setup and statistical analysis}

Each of the three experiments included a control and three debarking water treatment levels. We used five replicates of each of the three strains of G. sepiarium, I. benzoinum, and J. luteoalba. One strain of I. benzoinum was lost in experiment 1 . We used one single strain of each of the species $O$. lateritius and Phlebia sp. In experiment 1 we used fifteen replicates of each species, and in experiment 2 ten replicates of Phlebia sp. and five replicates of O. lateritius. In total this corresponds to $240-280$ individual trials per experiment.

Circular agar plugs with diameters of $18 \mathrm{~mm}$ were transferred from pure and well growing fungal cultures and placed in the centre of the prepared agar plates. The agar plates were stored at ambient temperature in the laboratory. The diameter of the growing mycelium (in $\mathrm{mm}$ ) was visually observed and measured with a ruler every second day for two weeks or until the mycelial growth reached the edge of the Petri dish. The growth rates (in $\mathrm{mm} / \mathrm{d}$ ) of the studied fungi were used as the response variables for the different treatments. Because of the large sample size in each experiment and the fact that the growth rates approached a normal distribution, we used a parametric analysis of covariance to characterize the effects of the two-factor treat- 
ment and species, including their interactions. We controlled for the pseudoreplication of individual strains by including it as an error term in the analysis. A separate analysis of variance was performed to explore the variation in response between strains of the same species for three of the investigated fungi (G. sepiarium, I. benzoinum, and J. luteoalba).

\section{Results and Discussion}

\section{Measurement of fungal growth}

The growth rate on agar of five species of fungi with various properties was used as parameter for the antifungal effect of debarking water. Linear growth was generally observed over the two weeks measurement period, although in some cases there was a short lapse of 2-3 days before growth began. In addition, the growth rates of some fungal species slowed down as their mycelia approached the edges of the agar plates.

The species and their individual strains responded differently to the extracts. Generally, the concentration test in experiment 1 revealed that the debarking water had antifungal effects, although a concentrated solution was required to achieve good antifungal activity (Fig. 1). Complete inhibition of growth was observed only for the single tested $O$. lateritius strain, two of the three G. sepiarium strains, and one of the three $J$. luteoalba strains. The greatest degree of variation between individual strains in terms of their response to the extract was observed for J. luteoalba.

In experiment 2 , the ethyl acetate fraction generally proved to be the most effective antifungal agent (Fig. 2). The fungi most sensitive to this fraction were the brown-rot fungi $G$. sepiarium and $O$. lateritius, which did not grow at all on the corresponding agar plates during the studied period. In addition, the growth of the white-rot fungus Phlebia sp., which grew rapidly on the control plates, was strongly reduced by the ethyl acetate extract in particular. The other fractions were generally less effective and in fact, $J . l u-$ teoalba exhibited accelerated growth on the agar plate containing the aqueous extract.

In experiment 3 , the diethyl ether fraction strongly reduced the growth of $G$. sepiarium, $O$. lateritius and Phlebia sp. The growth of the two latter species was also reduced by the other tested fractions. However, the

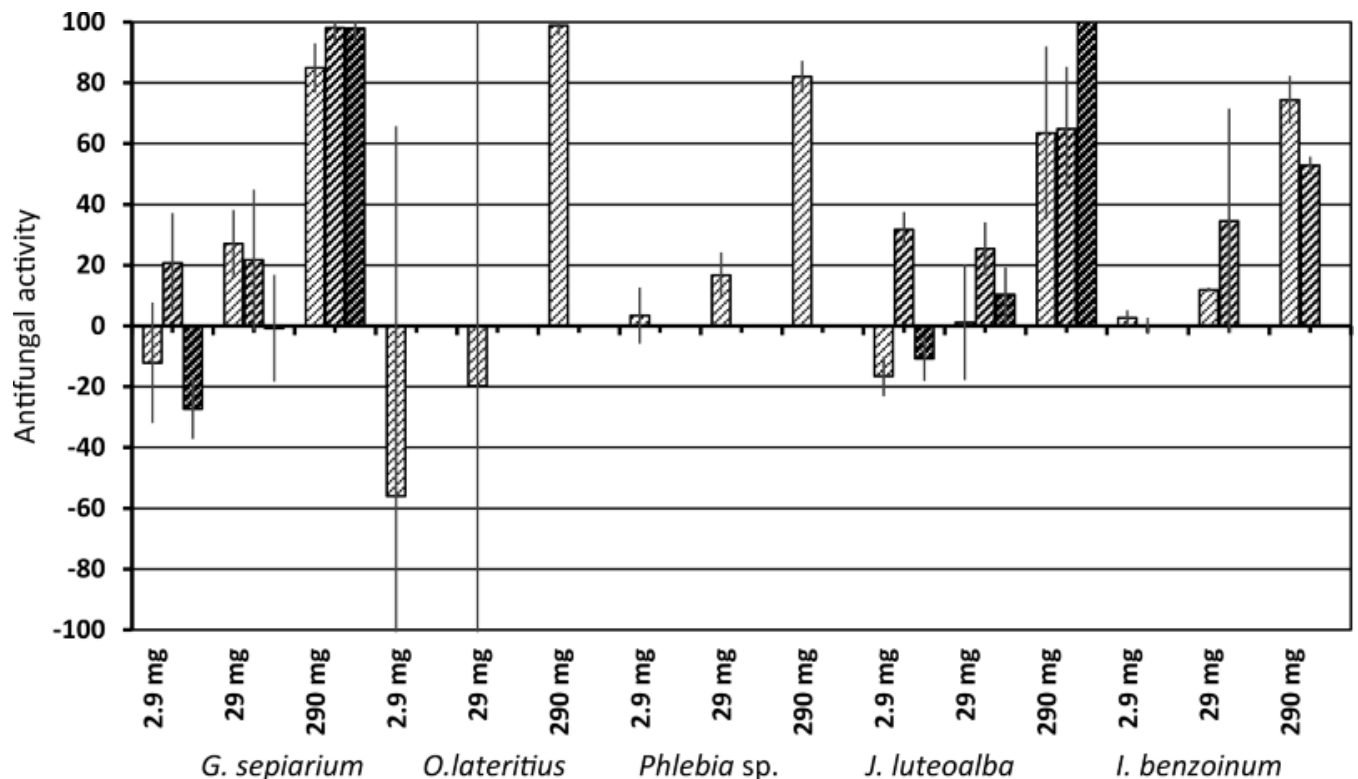

Fig. 1. Antifungal activity of the extracts in experiment 1, in which the fungi were exposed to different concentrations of freeze-dried and ethanol-extracted debarking water. Antifungal activity is calculated as $100 \cdot(C G-T G) / C G$, where $C G$ is the observed growth rate of fungal hyphae on the untreated control agar plate and $T G$ is the observed growth rate of fungal hyphae on the agar plate treated with debarking water. In cases where multiple bars are shown for a given species and extract concentration, the individual bars represent the response of one of the tested strains of that species. Only single strains of $O$. lateritius and P. cornea were examined. Each value is based on 5-15 replicates. Bars indicate SD. 


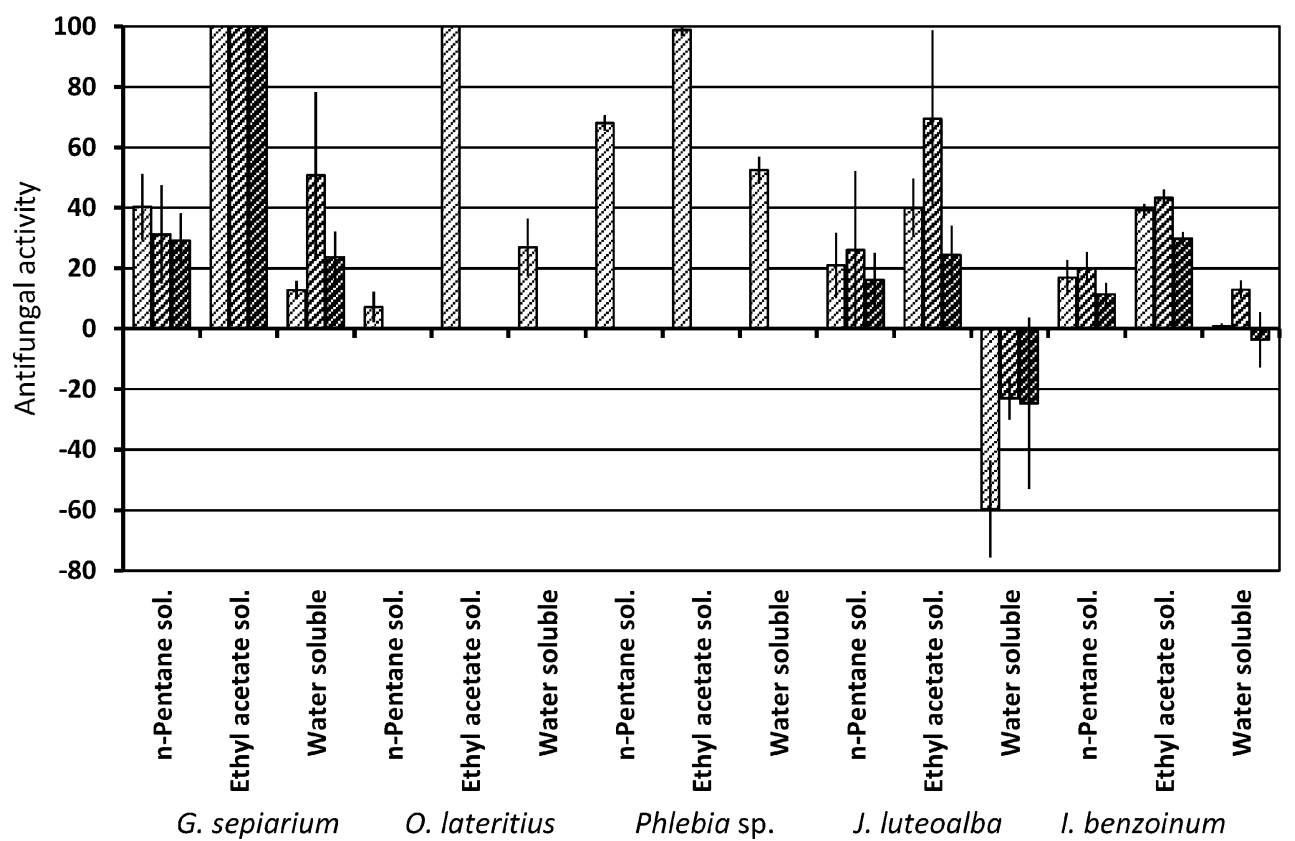

Fig. 2. Antifungal activity of the extracts in experiment 2, in which the fungi were exposed to different fractions of the debarking water. Antifungal activity was calculated as in Fig. 1 . The concentrations of the extracts correspond to $1 \mathrm{~g}$ of freeze-dried debarking water per agar plate, that is $0.43 \mathrm{~g} / \mathrm{L}$ of the $n$-pentane-soluble compounds and $3.09 \mathrm{~g} / \mathrm{L}$ of the ethyl acetate-soluble compounds. The yield of the water extraction is unknown as it was not completely dried. Each value is based on $5-10$ replicates. Bars indicate SD.

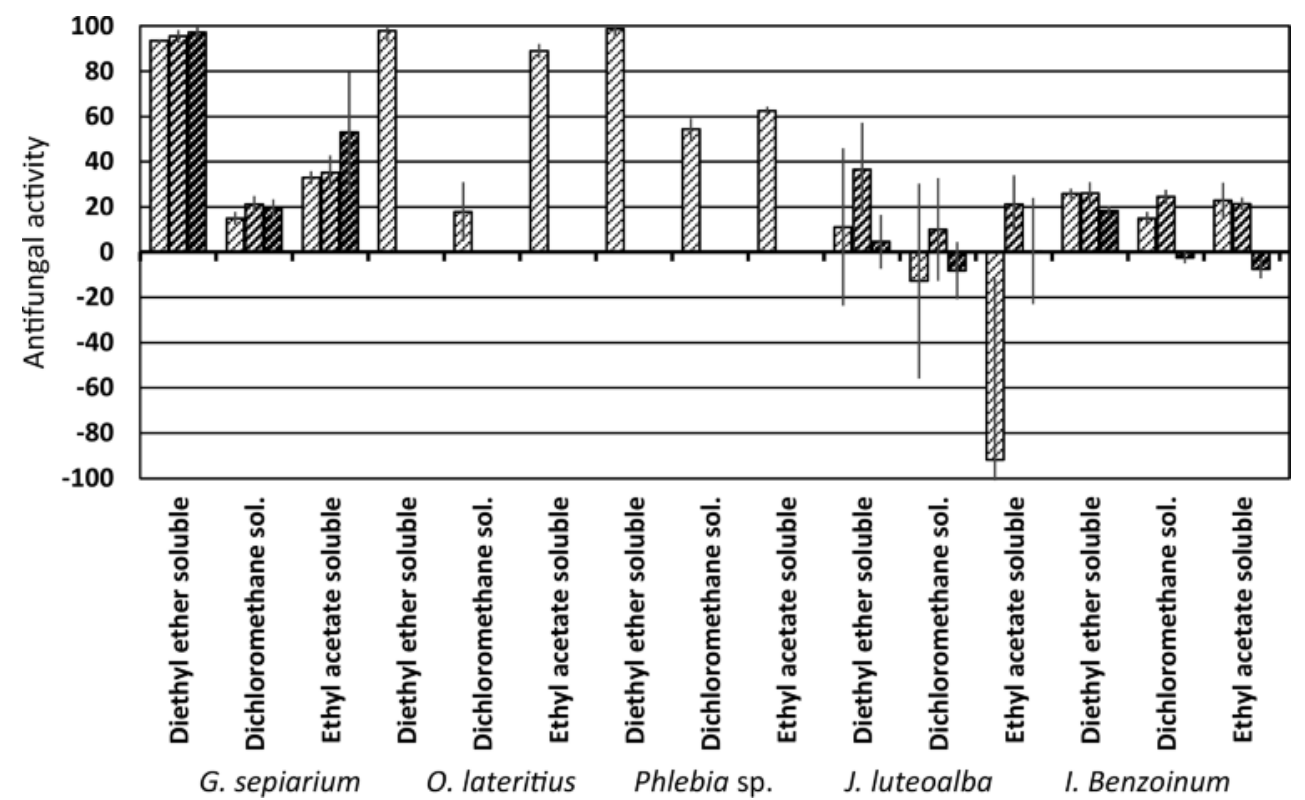

Fig. 3. Antifungal activity of the extracts in experiment 2, in which the fungi were treated with different fractions of the debarking water. Antifungal activity was calculated as in Fig. 1 . The concentrations of the extracts correspond to $1.1 \mathrm{~g}$ of freeze-dried debarking water, that is $1.42 \mathrm{~g} / \mathrm{L}$ of the diethyl ether-soluble compounds, $0.38 \mathrm{~g} / \mathrm{L}$ of the dichloromethanesoluble compounds, and $1.43 \mathrm{~g} / \mathrm{L}$ of the ethyl acetate-soluble compounds. Each value is based on $5-10$ replicates. Bars indicate SD. 
growth of I. benzoinum and J. luteoalba was affected only little (Fig. 3).

The brown-rot fungus G. sepiarium, which prefers fresh wood, was less tolerant to all fractions of the debarking water than species that prefer more decayed wood (see Figs. 1-3). It can also be seen that two of the tested white-rot fungi, I. benzoinum and $J$. $l u$ teoalba, were not much affected in any of the bioassays, and it can be noted that both species prefer more decayed wood. It is proposed that white-rot fungi are generally less affected by phenol growth inhibitors than brown-rot fungi, because of their higher laccase production, which enable them to detoxify aromatic compounds (Voda et al., 2003; Hart and Hillis, 1974).

\section{Statistical analysis}

In all three experiments, the treatment (concentration and extract type) and species effects were highly significant, as were their interactions $(p<0.001$ in all cases).

The individual strains of the species responded differently to the different extracts $(p<0.05)$ except for those of I. benzoinum in experiments 1 and 2 ( $p>0.05$ in both cases). This shows that not only the species themselves vary among each other, but also that different fungal strains have specific responses. These differences are, however, smaller than among species (cf. Figs. 1-3).

The growth responses of individual strains of a species to the concentration/extract type were significantly different in most cases, with the exception of $J$. luteoalba in experiment 2 and G. sepiarium in experiment 3 ( $p>0.05$ in both cases), suggesting that strains differ in their sensitivity to the different extract types, as shown in Figs. 1-3. However, these differences are less pronounced between strains as compared to species.

\section{Chromatographic analysis of the extracts}

TLC and HPLC analyses confirmed that, as expected, the solvent-solvent extraction process fractionated the debarking water such that its nonpolar contents, like terpenoids, were found in the $n$-pentane extract, compounds of intermediate polarity, like phenols and resin acids, were found in the ethyl acetate ex- tract, and its polar compounds, like sugars, were retained in the water/ethanol fraction. Each fractionation step reduced the concentrations of some compounds in the different extracts as they were split across several fractions. We therefore investigated extracts of increasing concentration as the material was fractionated further.

The ethyl acetate fraction contains a variety of phenolic substances, known to have an antifungal effect (Singh and Singh, 2010). These also have an antioxidant effect, which commonly causes growth inhibition on wood, due to the initial attack on the cell walls with reactive oxygen species. However, as we only tested growth on agar, effect of cell wall attack is not a plausible explanation for the phenols' fungicidal activity.

\section{Conclusion}

Spruce debarking waste water from the paper industry efficiently reduced the growth on agar of five species of wood-rot fungi, although the magnitude of reduction varied between the species and strains. The fractions obtained by solvent-solvent extraction using ethyl acetate and diethyl ether inhibited or strongly reduced growth in all strains of the two brown-rot species G. sepiarium and $O$. lateritius and also of the whiterot species Phlebia sp. Debarking waste water should therefore be further examined as an potential source of wood-protecting agents.

To meet the need of efficient and environmentally benign methods for wood protection screening of antifungal properties of debarking waste water should be extended to fungi growing on wood in order to verify any real wood protection action of extracts found active in the bio-assays. (Hsu et al., 2009; Chen et al., 2014; Hart and Hillis, 1974).

\section{Acknowledgement}

We are grateful for financial support from the EU (Objective 2, South Forest Counties region) and the County Administrative Board of Västernorrland. We also thank Oddmund Björkås for supplying us with debarking water from Ortviken paper mill in Sundsvall, Sweden, Joel Ljunggren for management of the Mid Sweden University Fungal Collection, and Rabiull Alam for assisting with some initial experiments with the fungi. 
Allen L. and Back E. (eds.) (2000), Pitch Control, Wood Resin and Deresination. Tappi Press, Atlanta, GA, USA.

Bowyer J. L., Shmulsky R., and Haygreen J. G. (2003), Wood durability and protection. In: Forest Products and Wood Science, 4th ed. (Bowyer J. L., Shmulsky R., and Haygreen J. G., eds.). Iowa State Press, Ames, IA, USA, pp. $261-286$.

Chen P.-S., Chen Y.-H., Yeh T.-F., and Chang S.-T. (2014), Mechanism of decay resistance of heartwood extracts from Acacia confuse against brown-rot fungus Laetiporus sulphureus. Wood Sci. Technol. 48, 451-465.

Co M., Fagerlund A., Engman L., Sunnerheim K., Sjöberg P., and Turner C. (2012), Extraction of antioxidants from spruce (Picea abies) bark using eco-friendly solvents. Phytochem. Anal. 32, 1-11.

Duke J. A. (1985), Handbook of Medicinal Herbs. CRS Press, Inc., Boca Raton, FL, USA.

Geissman T. A. (1963), Flavonoid compounds, tannins, lignins and related compounds. In: Pyrrole Pigments, Isoprenoid Compounds and Phenolic Plant Constituents, Vol. 9 (Florkin M. and Stotz E. H., eds.). Elsevier, New York, USA, pp. 215-250.

Goodell B. (2003), Brown-rot fungal degradation of wood: our evolving view. In: Wood Deterioration and Preservation: Advances in our Changing World (Goodell B., Nicholas D. D., and Schultz T. P., eds.). American Chemistry Society, Washington DC, USA, pp. 97-118.

Green F. and Highley T. L. (1997), Mechanism of brown-rot decay: paradigm or paradox. Int. Biodeter. Biodegr. 39, $113-124$.

Harmon M. E., Franklin J. F., Swanson F. J., Sollins P., Gregory S. V., Lattin J. D., Anderson N. H., Cline S. P., Aumen N. G., Sedell J. R., Lienkaemper G. W., Cromack Jr. K., and Cummins K. W. (1986), Ecology of coarse woody debris in temperate ecosystems. Adv. Ecol. Res. 15, $133-302$.

Hart J. H. and Hillis W. E. (1974), Inhibition of wood rotting fungi by stilbenes and other polyphenols in Eucalyptus siderioxylon. Phytopathology 64, 939-948.

Hsu F. L., Chen P. S., Chang H. T., and Chang S. T. (2009), Effects of alkyl chain length of gallates on their antifungal property and potency as an environmentally benign preservative against wood-decay fungi. Int. Biodeterior. Biodegr. 63, $543-547$.

Kylliäinen O. and Holmbom B. (2004), Chemical composition of components in spruce bark waters. Paperi ja Puu 86, 289-292.
Leonowicz A., Matuszewska A., Luterek J., Ziegenhagen D., Wojtas-Wasilewska M., Nam-Seok C., Hofrichter M., and Rogalski J. (1999), Biodegradation of lignin by white rot fungi. Fungal Genet. Biol. 27, $175-185$.

Mason T. L. and Wasserman B. P. (1987), Inactivation of red beet beta-glucan synthase by native and oxidized phenolic compounds. Phytochemistry 26, 2197 - 2202.

Messner K., Frackler K., Lamaipis P., Gindl W., Srebotnik E., and Watanabe T. (2003), Overview of whiterot research: where we are today. In: Wood Deterioration and Preservation: Advances in our Changing World (Goodell B., Nicholas D. D., and Schultz T. P., eds.). American Chemistry Society, Washington DC, USA, pp. $73-96$.

Renvall P. (1995), Community structure and dynamics of wood-rotting Basidiomycetes on decomposing conifer trunks in northern Finland. Karstenia 35, 1-51.

Schultz T. P., Nicholas D. D., and Preston A. F. (2007), A brief review of the past, present and future of wood preservation. Pest Manag. Sci. 63, $784-788$.

Singh T. and Singh A. P. (2010), A review on natural products as wood protectant. Wood Sci. Technol. 46, $851-870$.

Suzuki M. R., Hunt C. G., Houtman C. J., Dalebroux Z. D., and Hammel K. E. (2006), Fungal hydroquinones contribute to brown rot of wood. Environ. Microbiol. 8, $2214-2223$.

Tedersoo L., Suvi T., Jairus T., and Koljalg U. (2008), Forest microsite effects on community composition of ectomycorrhizal fungi on seedlings of Picea abies and Betula pendula. Environ. Microbiol. 10, 1189-1201.

Voda K., Boh B., Vrtačnik M., and Pohleven F. (2003), Effect of the antifungal activity of oxygenated aromatic essential oil compounds on the white-rot Trametes versicolor and the brown-rot Coniophora puteana. Int. Biodeterior. Biodegr. 51, 51-59.

Yang D. Q. (2009), Potential utilization of plant and fungal extracts for wood protection. For. Prod. J. 59, 97-103.

Yang D. Q., Wang X. M., Shen J., and Wan H. (2004), Antifungal properties of barks of various wood species. For. Prod. J. 54, $37-39$.

Yelle D. J., Ralph J., Lu F., and Hammel K. E. (2008), Evidence for cleavage of lignin by a brown rot basidiomycete. Environ. Microbiol. 10, 1844 - 1849. 